Peasant identity, racialization and citizenship in Imperial Brazil: a discussion of Guillermo Palacios' 'War of the Hornets'"

\title{
Identidade camponesa, racialização e cidadania no Brasil monárquico: 0 caso da 'Guerra dos Marimbondos' em Pernambuco a partir da leitura de Guillermo Palacios.
}

Hebe Maria Mattos

Professora da Universidade Federal

Fluminense, Rio de Janeiro

\section{Resumo}

0 presente texto comenta o artigo de Guillermo Palacios 'A Guerra dos Marimbondos: uma revolta camponesa no Brasil escravista', escrito em 1984. Tal texto se apresenta ainda hoje como a principal analise sobre o movimento sedicioso contra os Decretos 797 e 798 de 18 de junho de 1851 que mandavam 'executar o regulamento para a organização do censo geral do Império' e 'executar o regulamento do registro de nascimento e óbitos'. 0 regulamento seria também conhecido pelos revoltosos como 'Lei do Cativeiro'. O uso da noção de camponês, presente desde o titulo do artigo e fundamental para a conclusão do trabalho, é o primeiro ponto discutido no texto, levando em consideração, em especial, as vicissitudes teóricas e historiográficas do termo. Como segundo ponto de discussão, a luz de questões colocadas pela historiografia recente sobre o Brasil monárquico, propõe-se uma revisão da oposição apresentada na conclusão do artigo entre o caráter classista e camponês da revolta - que o autor demonstra - com as apreensões mais comuns dela nas fontes de época, como um movimento de 'homens de cor' insuflados por idéias liberais.

\begin{abstract}
This text discusses Guillermo Palacios' paper "Peasant rebellions in Brazilian slave based society: the 'War of the Hornets' (Pernambuco, 1851-1852)", originally written in 1984. Until today Palacios' paper remains the best analyses of the rebellious movement that rose against the Imperial Decrees 797 and 798, both issued on June $18^{\text {th }} 1851$, which ordered the implementation of a national census and also the civil registration of newborns and deceased in the Empire. Those decrees became then known as the "Law of Captivity". The present discussion starts with a debate of the author's use of the concept of peasant, in its theoretical and historiographical implications; a concept that appears not only in the title of Palacios' paper, but is also crucial for his conclusions concerning the movement. Considering the recent historiographical debates about Imperial Brazil, the text deals also with the opposition presented in Palacios' conclusion, on one side his interpretation of the movement as a peasant and class based rebellion and, on the other side, the more usual understanding, by those who were contemporary to the upheaval, as a movement lead by "non whites" instilled by liberal ideas.
\end{abstract}

\section{Palavras-chave}

escravidão, homens livres pobres, revolta / rebelião, história social, Império do Brasil, identidades.

\section{Keywords}

slavery, poor free people, uprising / rebellion, social history, Brazilian Empire, identities 
Cf. Palacios, Guillermo.Revoltas Camponesas no Brasil Escravista: a 'Guerra dos Maribondos' (Pernambuco, 1851-1852). Revista Almanack Braziliense, N.3, maio de 2006.

Cf. Palacios, Guillermo. Campesinato e escravidão no Brasil: Agricultores livres pobres na Capitanina Geral de Pernambuco (1700-1817) Brasilia, Editora UnB, 2004

Cf. Palacios, Guillermo. Campesinato e Escravidão no Brasil, op. Cit, p.14.
0 texto de Palacios "A Guerra dos Marimbondos: uma revolta camponesa no Brasil escravista", escrito em 1984, se apresenta ainda hoje como a principal análise sobre o movimento sedicioso contra os Decretos 797 e 798 de 18 de junho de 1851 que mandavam "executar o regulamento para a organização do censo geral do Império" e "executar o regulamento do registro de nascimento e óbitos", que seria também conhecido como "lei do cativeiro"1. Tem ainda a vantagem de trazer à luz a documentação de Pernambuco sobre o movimento, quando a maioria dos demais trabalhos que fazem menção ao mesmo utilizam principalmente a documentação reunida nos arquivos do Ministério da Justiça, localizada no Arquivo Nacional do Rio de Janeiro.

0 texto redefiniu as percepções sobre o tempo e o espaço da revolta, mostrando que ela ultrapassava as fronteiras seja da produção de canade-açucar, seja das áreas de subsistência do Agreste, tendo ramificações por várias províncias do Nordeste (Pernambuco, Alagoas, Paraiba, Sergipe, Ceará e até Minas Gerais). Neste sentido, apesar de sua ênfase em Pernambuco e ali na região de agricultura de subsistência, o artigo põe em relevo a extensão e diversificação econômica da população livre do nordeste na primeira metade do século XIX e, indiretamente, as bases camponesas de sua reprodução social.

Depois do texto sobre a Guerra dos Marimbondos, Palacios escreveria "Campesinato e Escravidão", uma das mais abrangentes abordagens históricas sobre a emergência de um campesinato no nordeste brasileiro e de suas relações com a sociedade escravocrata e com o estado colonial português desde o século XVII². Segundo a introdução do mesmo:

"Enquanto preparava a versão definitiva do texto (sobre a Guerra dos Marimbondos) ... pareceu-me que uma das operações imprescindiveis para dar 'corpo' ao estudo seria traçar a origem social e espacial dos núcleos camponeses que chefiaram a revolta de 1852, nascida na região compreendida pelos municípios pernambucanos de Pau d'Alho, Limoeiro e São Lourenço da Mata"3.

Escolhi, assim, como primeiro ponto a desenvolver nestes meus comentários, discutir o uso da noção de camponês para os livres e pobres no Brasil escravista e as vicissitudes teóricas e historiográficas do termo.

Em seu livro, Palacios nos mostra através de extensa pesquisa como tais grupos se formaram e conseguiram se relacionar com o mercado internacional através de produtos como o tabaco e o algodão, mesmo sem contar com qualquer apoio direto das estruturas estatais portuguesas. Destaca também seu papel central para o abastecimento interno não apenas da colônia brasileira mas das tropas e estruturas imperiais portuguesas. Bem como põe em relevo seus confrontos com tais mecanismos, especialmente através da resistência ao recrutamento militar que recaía pesadamente sobre as populações rurais. Não aprofunda porém o acesso, mesmo que eventual, desses produtores ao trabalho escravo. No livro, como no artigo sobre a Guerra dos Marimbondos, o autor tem como pressuposto o caráter marginal e em contradição com as estruturas escravistas dominantes das populações em questão.

A idéia da Guerra dos Marimbondos como uma revolta camponesa é um dos eixos centrais do texto aqui analisado. $\mathrm{Na}$ interpretação de Palacios, a guerra dos Marimbondos foi um movimento de resistência às perspesctivas de proletarização encaminhadas pelo novo estado brasileiro com a aprovação do fim do tráfico atlântico e a aprovação da lei de terras, pois "os agricultores autônomos de base camponesa eram a primeira linha de 
Cf. Palacios, Guillermo. Revoltas camponesas no Brasil escravista, op Cit.

Cf. Palacios, Guillermo. Revoltas camponesas no Brasil escravista, op. Cit.

Cf. Motta, Marcia M. M. "Historia Social da Agricultura Revisitada. Um diálogo com Maria Yedda Leite Linhares". In: Mattos, Hebe Fragoso J. L. - Silva, F. C. T. (org.). Escritos sobre História e Educação: homenagem à Maria Yedda Leite Linhares. Rio de Janeiro: Mauad/Faperj. 2001.

Cf. Mattos, Hebe. "Campesinato e Escravidão" . In: Mattos, Hebe - Fragoso J. L. - Silva, F. C. T. (org.). Escritos sobre História e Educação: homenagem à Maria Yedda Leite Linhares. Rio de Janeiro: Mauad/Faperj, 2001.

Sobre esta questão, cf. Rios, Ana L. e Mattos, Hebe. "A última geração de libertos e a historiografia sobre o pós-abolição no Brasil" In: Topoi. Revista do Programa de Pos-Graduação em Historia da UFRJ, n. 8, 2005. reserva de mão-de-obra para as plantations no início da crise terminal do escravismo"4. Enquanto revolta camponesa, porém, era também "uma defesa indireta da ordem anterior" ou seja, da escravidão, pois "enquanto houvesse escravos, o homem pobre continuaria sendo pobre, mas livre" 5 .

Neste sentido, trata-se uma revolta camponesa e ao mesmo em defesa da escravidão. Demasiadamente informado por uma perspectiva sistêmica, predominante nas análises historiográficas dos anos 1980, o texto não desenvolve todas as conseqüências dessa dupla afirmação. 0 trabalho escravo ampliava a autonomia desses produtores, tornando-os sujeitos ao recrutamento militar, mas não a outras formas de trabalho compulsório. Uma relativa prosperidade econômica, o acesso eventual à propriedade escrava, e a tessitura de redes horizontais e verticais de relações pessoais podiam, de fato, colocá-los a salvo também das pressões do Estado. Buscar entender as ambigüidades da inserção social dos segmentos livres e pobres na ordem colonial ou monárquica me parece fundamental para compreender a vitória final do movimento aqui considerado e a efetiva suspensão da execução dos regulamentos contra os quais os camponeses do nordeste se levantaram em meados do século XIX.

No conjunto da historiografia brasileira a utilização da expressão "camponês" é bastante controversa. Por sua abrangência, a palavra camponês perde historicidade e por isso muitos historiadores tendem a recusá-la. Além disso, os altos níveis de mobilidade espacial e o acesso eventual dos roceiros livres ao trabalho escravo problematizam ainda mais a aplicabilidade do termo para o Brasil escravista ${ }^{6}$. Por outro lado, as pesquisas empíricas sobre os livres e pobres desde os anos 1980, em diversas regiões, têm cada vez mais enfatizado a valorização do trabalho familiar, do acesso direto à terra (mediante propriedade ou usufruto) e de um elevado grau de autonomia na gestão das atividades econômicas como elementos centrais do modo de vida de amplas camadas no meio rural, com um acesso limitado ao trabalho escravo diretamente relacionado ao ciclo de vida familiar7. De todo modo, apenas após o fim do tráfico atlântico, o trabalho escravo se tornaria efetivamente inacessivel aos livres pobres de uma maneira geral. Neste sentido, até que ponto é possivel abordar, no contexto da crise da escravidão no Brasil, em vez da crise de um campesinato colonial, como quer Palacios no seu texto sobre os Marimbondos, a emergência e consolidação de uma identidade camponesa, antes bastante ambígua? As bases das negociações relativas à criação de novos modos de coerção da força de trabalho no mundo rural pós-emancipação certamente estiveram assentadas na crise das formas de reprodução do modo de vida anterior, diretamente relacionado à existência do trabalho escravo, mas também estiveram assentadas em uma cultura camponesa, que se explicita historicamente exatamente a partir da crise da escravidão 8

Observadas deste ponto de vista, as lutas contra as ameaças de proletarização produzidas pelo "início da crise terminal do escravismo", para usar uma expressão do autor, nas quais se incluiria a Guerra dos Marimbondos, teriam, em seu conjunto, reforçado a identidade camponesa dos agricultores em questão, em vez de enfraquecê-la. Apesar da perda relativa de autonomia em relação aos grandes proprietários e ao Estado que acompanhou o processo.

Não sustento com isso que seja incorreto ou inválido caracterizar a emergência de um campesinato no nordeste brasileiro ao longo do período colonial, apesar do acesso eventual ao trabalho escravo. Pelo contrário, 
Neste sentido, cf. Mattos, Hebe. "Campesinato e Escravidão", op. cit.

10

Cf. Palacios, Guillermo. Revoltas camponesas no Brasil escravista, op. Cit.

11

Cf. Palacios, Guillermo. Revoltas camponesas no Brasil escravista, op. Cit. acho que a noção enriquece a análise da especificidade econômica destas populacões no contexto da sociedade escravista9. Não apenas a cronologia da revolta, diretamente associada ao calendário agrícola, mas também sua geografia, mais intensa nas áreas onde a reprodução econômica do campesinato estaria comprometida, como nas antigas áreas produtoras de algodão, formam indícios eloquentes dos sentido camponeses do movimento em questão. A crise de autonomia reforça a identidade camponesa que se constituirá na base das negociações de novas formas de subordinação social.

Voltando ao texto de Palacios, ele opõe este sentido camponês, invisivel aos comentaristas de época, às versões produzidas pelos contemporâneos para explicar a revolta.

A primeira dessas versões, veiculada por algumas vozes conservadoras, defendia que a nova sedição seria produto da ação dos antigos praieiros e de seus ideais liberais sobre as populações ignorantes do mundo rural. Contra esta argumentação, o artigo destaca diversas alianças entre políticos conservadores e liberais de Pernambuco para combater e desqualificar o movimento. Por outro lado, o autor admite que foi exatamente o temor dos resquícios do movimento praieiro que fez a documentação de Pernambuco tão mais abundante que a das outras provincias.

Fato é que os gritos de "viva a liberdade" e alguns "morram os guabirus" não faltaram aos revoltosos. Não estarem "insuflados" por antigos líderes praieiros não elimina as evidências de que leituras especificas e muitas vezes localizadas do ideário liberal, especialmente de defesa da liberdade civil contra o poder do Estado, ocuparam um lugar importante na legitimação do movimento. Da mesma maneira, a influência da igreja sobre as populações rurais apresenta-se como aspecto cultural relevante, que não será aqui aprofundado, mas que (me parece) não pode ser relegado a mera cortina de fumaça no desdobrar dos acontecimentos.

A segunda explicação presente nas fontes de época, especialmente do Ministério da Justiça, considera que a revolta era provocada pela idéia equivocada de que o registro de nascimento e óbitos e, indiretamente, a Lei do Censo teriam por objetivo escravizar a gente de cor. 0 fato das fontes locais enfatizarem menos este aspecto, pondo em relevo a participação de matutos de uma maneira geral e não apenas de "gente de cor" nos levantes locais, destacado pelo autor, não permite eliminar a importância das tensões étnico-raciais na configuração da revolta. Especialmente, no que se refere ao fato de que este parece ter sido um aspecto central para a decisão final do estado monárquico de ceder às reivindicações dos insurgentes.

Nas palavras de Palacios: "a 'Guerra dos Marimbondos' - na batalha de 1852 - foi 'ganha' pelos livres e pobres, que forçaram o impávido Império a capitular e suspender a aplicação do Registro dos Nascimentos e Óbitos por mais de quarenta anos, assim como conseguiram deter por mais de duas décadas as tentativas do Estado para os contar."10

$\mathrm{Na}$ verdade, se parece haver um consenso entre as elites políticas do Recife ou do Rio de Janeiro sobre a ignorância dos revoltosos, no nível local estes reuniam simpatias e, exatamente por isso, a repressão ao movimento tornou-se extremamente problemática.

Conforme as fontes citadas por Palacios, os grupos armados da guarda nacional em vez de reprimirem os revoltosos juntavam-se a eles. "...esta gente (as milícias) compactua com os sublevados de outras comarcas contra o Decreto de 18 de junho de 1851"11 nos diz uma das vozes de época. 
12

Sobre a noção de cidadania na Constituição do Brasil de 1824 cf., entre outros, Mattos, Hebe. Escravidão e Cidadania no Brasil Monárquico. Rio de Janeiro, Jorge Zahar Ed., 2000; Carvalho, José Murilo. Cidadania no Brasil. O Longo Caminho. Rio de Janeiro: Civilização Brasileira, 2003, cap. 1. e Kraay, H. Race, State, and Armed Forces in Independence-Era Brazil. Bahia, 1790-1840. Stanford: Stanford University Press, 2001, cap. 1

13

Cf. Biblioteca Nacional - Obras Raras - Coleção Antônio Pereira rebouças- "Biografia do advogado conselheiro Antônio Pereira Rebouças". S.d., 1837[?]. Para uma análise pormenorizada do episódio, cf. Grinberg, K. O Fiador dos Brasileiros. Cidadania, escravidão e direito civil no tempo de Antônio Pereira Rebouças. Rio de Janeiro: Civilização Brasileira , 2002, p. 77.

14

Cf. Costa, E. V. Da Monarquia à República: momentos decisivos. São Paulo: LECH 1979, cap. 1: Ribeiro, G. S. A Liberdade em Construção. Identidade nacional e conflitos antilusitanos no Primeiro Reinado. Rio de Janeiro: FAPERJ/Relume Dumará, 2002, cap. 1; Lima, I. S. Cores, marcas e falas: sentidos da mestiçagem no Império do Brasil. Rio de Janeiro: Arquivo Nacional, 2003, parte 1.
Como segundo ponto de discussão, proponho, então, rever a oposição apresentada na conclusão entre o caráter classista e camponês da revolta - que Palacios demonstra - com as apreensões mais comuns dela, nas fontes de época, como um movimento de "homens de cor" insuflados por idéias liberais.

A emergência da questão racial no mundo atlântico escravista não tem qualquer relação com as estruturas estamentais de antigo regime que legitimavam originalmente a escravidão. Está, antes, diretamente relacionada às revoluções atlânticas e às concepções de igualdade de direitos adotadas nos novos estados nacionais surgidos a partir delas. E, neste sentido, para além de uma base camponesa, a revolta dos marimbondos parece combinar elementos modernos, como noções de direitos e cidadania, que cada vez mais ampliavam sua circulação em função das revoltas liberais, com elementos constitutivos da ordem estamental escravista, especialmente a possibilidade de trânsito entre a escravidão e a liberdade (e vice-versa), configurando situações de legalidade e ilegalidade da condição de escravidão.

Neste sentido, a recusa e as dificuldades da guarda nacional em reprimir o movimento, bem como a vitória dos marimbondos em termos das reivindicações básicas de supressão da execução do regulamento, precisam ser entendidas no contexto das disputas em torno dos significados da cidadania e dos novos direitos inscritos na constituição de 1824 e não apenas das pressões econômicas sobre as populações camponesas.

A manutenção da escravidão pela Constituição de 1824, mesmo que com base apenas no direito de propriedade, e a restrição legal ao gozo pleno dos direitos políticos aos libertos acabaram por tornar o que hoje chamaríamos de "discriminação racial" uma questão crucial na vida de amplas camadas das populações urbanas e rurais do periodo ${ }^{12}$. Apesar da igualdade de direitos civis entre os cidadãos, reconhecida pela Constituição, os brasileiros não-brancos continuavam a ter até mesmo o seu direito de ir e vir dramaticamente dependente do reconhecimento costumeiro de sua condição de liberdade. Se confundidos com cativos ou libertos, estariam automaticamente sob suspeita de serem escravos fugidos - sujeitos, então, a todo tipo de arbitrariedade, se não pudessem apresentar sua carta de alforria.

Em sua autobiografia manuscrita, Antônio Pereira Rebouças informa que, ao viajar de Salvador até o Rio de Janeiro, em 1823, logo após os eventos que resultaram na independência do país, quase foi embaraçado de continuar a viagem em Porto Seguro, só tendo sido autorizado a prosseguir pelo juiz municipal, valendo-se do "conhecimento que já aí tinham de seu nome e a persuasão de sua identidade pelo conhecimento pessoal que manifestou ter das mais notáveis ocorrências patrióticas e profissionalmente da legislação em matéria forense"13. Neste contexto, a igualdade de direitos entre os cidadãos brasileiros livres, para além das diferenças de cores, esteve em foco em todas as ocasiões em que a participação popular se fez presente no processo de independência política e empolgou expressivas lideranças das elites políticas liberais, em especial entre os liberais ditos "exaltados" 14.

$\mathrm{Na}$ verdade, esta igualdade foi uma invenção do processo de independência, pois os chamados "estatutos de pureza de sangue" ainda limitavam o acesso a cargos públicos, eclesiásticos e a títulos honoríficos a descendentes de negros e mulatos no espaço colonial. Tal legislação remontava em Portugal às Ordenações Afonsinas [1446/7], atingindo os descendentes de 
15

Cf. Carneiro, M. L. T. Preconceito Racial. Portugal e Brasil-colônia. São Paulo: Brasiliense, 1988.

\section{6}

Epigrafe do jornal O Mulato ou Homem de Cor (Biblioteca Nacional, 1833). Sobre a presença destes jornais no panorama político da Corte no periodo regencial, cf. Souza, "Mentalidade escravista e abolicionismo entre os letrados da Corte (1808-1950)". Dissertação de Mestrado em História, Niterói, UFF, 1994; Viana, L. "As dimensões da cor: um estudo do olhar norteamericano sobre as relações interétnicas. Rio de Janeiro, primeira metade do século XIX." Dissertação de Mestrado em História, Niterói, UFF, 1998, e Lima, I. S. Cores, marcas e falas: sentidos da mestiçagem no Império do Brasil. Rio de Janeiro: Arquivo Nacional, 2003, cap. 1.

17

Cf. Mattos, Hebe. Das Cores do Silêncio. Significados da Liberdade no Sudeste Escravista. Rio de Janeiro, Nova Fronteira, 1998, cap. 9.

18

Cf. Vaz, N. "Formação do Exército Brasileiro e sua Evolução no Século XIX" In: RIHGB, 1922, pp. 621-681 (p. 628); Ribeiro, G. S. A Liberdade em Construção...Op. Cit., 2002, p. 257. mouros e judeus. As Ordenações Manuelinas [1514/21] estenderam as restrições também aos descendentes de ciganos e indígenas e as Ordenações Filipinas [1603] acrescentaram à lista os negros e os mulatos. As reformas pombalinas revogaram explicitamente as restrições aos descendentes de judeus, mouros e indígenas, em todo o Império Português, mas as relativas aos descendentes de africanos se manteriam no espaço colonial, para só serem explicitamente rompidas, no Brasil, pela Constituição de 182415.

Nos primeiros anos do período regencial, proliferaram no Rio de Janeiro pasquins exaltados com sugestivos títulos como $O$ homem de cor, $O$ Brasileiro Pardo, O Mulato ou O Cabrito - todos argüindo sobre igualdade de direitos entre os cidadãos brasileiros, independentemente da cor, garantida na Constituição. No Brasil, diziam, "não há mais que escravos ou cidadãos" e, portanto, "todo cidadão pode ser admitido aos cargos públicos civis e militares, sem outra diferença que não seja a de seus talentos e virtudes"16. Este tipo de discurso no campo mais amplo do liberalismo oitocentista não significa que a procura por líderes praieiros que "manipulassem" as massas ignorantes presente nas fontes oficiais ligadas ao conservadorismo fizesse algum sentido. Mas a circulação das novas idéias liberais e as apropriações específicas delas pelas camadas camponesas não podem ser descartadas como fermento da revolta e da forma específica - de luta por direitos - que veio a assumir.

Com a constituição de 1824, a cor das pessoas livres deixou de implicar legalmente restrições ao acesso a cargos públicos e posições de prestígios no novo Império do Brasil. A ordem que se devia registrar a cor dos escravos e não das pessoas livres na Lei do Censo, revelava o consenso social sobre tal ponto. Porém, a ordem de se registrar a cor dos escravos, tornava os mais desvalidos entre os livres pobres e libertos extremamente vulneráveis a tentativas de escravização ou reescravização.

No que se refere ao registro civil a ameaça era ainda mais grave. Afinal, a condição civil de uma pessoa era legalmente decidida no registro paroquial, ali se encontravam os livros dos "livres" e dos "escravos". A alcunha de "Lei do Cativeiro" é neste sentido extremamente significativa e precisa ser entendida no contexto da época. Não pode ser reduzida apenas a uma má apreensão da lei mas não se trata também de uma apreensão super consciente de seus sentidos modernizantes no sentido de formar um mercado de trabalho livre. Para os revoltosos era realmente essencial que eles fossem ouvidos sobre que instâncias consideravam confiáveis para registrar se seus filhos haviam nascido livres, libertos ou escravos. Reescravizações com base neste tipo de expediente não eram incomuns, mesmo sob a égide do controle paroquial 17 . Porque os párocos locais pareciam mais confiáveis aos revoltosos que as novas faces do Estado nacional em formação é questão a ser mais aprofundada pela pesquisa histórica na região.

Isto não quer dizer que apenas os livres de cor participassem da revolta, as questões relativas à resistência ao recrutamento e ao direito de propriedade que também se afiguraram no movimento bem o demonstram. Mas o caráter camponês da revolta não é antagônico aos sentidos raciais e políticos que lhes são atribuidos pelos observadores de época.

Aliás, a própria questão do recrutamento, além dos óbvios desdobramentos econômicos, especialmente quando envolvia deslocamento espacial, não pode ser pensada sem levar em conta tais sentidos raciais e políticos.

Um Alvará de 22 de março de 1766 aboliu o recrutamento segregado por grupos de status/cor nas tropas regulares do Exército Real na colônia brasileira, ao mesmo tempo em que criou os chamados Corpos Auxiliares ${ }^{18}$. 
19

Cf. Kraay, H. Race, State, and Armed Forces in Independence-Era, op. Cit., 2001, pp. 76-77.

20

Cf. Palacios, G. Campesintato e escravidão no Brasil, op. Cit., 2004, cap. V.

21

Cf. Ribeiro, G. S. A liberdade em Construção. op. Cit., pp. 257 e seguintes; Kraay, H. Race, State and Armed Forces in IndependenceEra, op. Cit., cap. 4, e Kraay, H. "Identidade racial na política, Bahia, 1790-1840: o caso dos Henriques". In: Jancsó, Istvan. Brasil: Formação do Estado e da Nação. São Paulo: FAPESPHucitec. 2003; e Silva, L. G. "Negros Patriotas. Raça e identidade social na formação do Estado Nação (Pernambuco, 1770-1830)". In: JANCSÓ, Istvan. Brasil: Formação do Estado e da Nação. São Paulo: FAPESP-HUCITEC, 2003.

22

Cf. Schwartz, S. Segredos Internos: engenhos e escravos na sociedade colonial (15501835). São Paulo: Companhia das Letras, 1988, cap 16; Barickman, B. "As Cores do Escravismo: escravistas "pretos", "pardos" e "cabras" no Recôncavo Baiano, 1835". In: População e Família. São Paulo, no 2, pp. 7-59, 1999; Mattoso. K. Q. Da Revolução dos Alfaiates à Riqueza dos Baianos no Século XIX. Itinerário de Uma Historiadora. Salvador: Corrupio, 2004, pp. 225-261.

23

BN, Sessão de Periódicos, O Mulato ou 0 Homem de Cor, 4 de novembro de 1833.
A tendência após esta data foi que prevalecesse apenas o recrutamento de brancos ou "pardos claros" nas tropas de linha da colônia. Pelo menos enquanto determinação oficial ${ }^{19}$. Isto terá uma indicência bastante dramática sobre o campesinato de origem européia do nordeste oriental no contexto das guerras coloniais do final do século XVIII, como nos mostra Palacios no livro Campesinato e Escravidão 20.

Já nos Corpos Auxiliares, apesar das determinações legais, permaneceram os Terços e os Regimentos divididos entre brancos, pardos e pretos até a criação da Guarda Nacional em 183121. Com expressiva preferência dos agentes locais pelo recrutamento das populações camponesas "de cor", toda vez que esta escolha era possivel.

Por outro lado, grande parte da população de cor era ou pretendia ser possuidora de escravos. Se continuamos com o exemplo do Recôncavo Baiano, principal área exportadora do final do período colonial, onde há um bom volume de pesquisas sobre padrão de posse de escravos, sabemos que ali a maior parte dos cativos morava em propriedades de menos de 20 escravos e cerca de $80 \%$ dos proprietários de escravos possuiam menos de 10 cativos. Entre estes pequenos senhores, a presença de descendentes de africanos era comum, incluindo muitos libertos, por vezes eles próprios vindos da África 22 .

$\mathrm{Se}$, conforme desenvolvido anteriormente, a moderna noção de raça foi uma construção social estreitamente ligada, no continente americano, às contradições entre os direitos civis e políticos, inerentes à cidadania estabelecida pelos novos estados liberais, e o longo processo de abolição do cativeiro - esta construção, no Brasil, se fez de forma especialmente problemática. Apesar de todo o preconceito com base na cor e na "qualidade" dos homens livres das elites sociais e políticas do novo país - herança da colonização portuguesa - do ponto de vista dos interesses escravistas existentes no Brasil, em seu sentido mais amplo, em grande medida compartiIhados por boa parte da população de "pardos" livres, a moderna noção de raça não se apresentava como solução, mas, antes, como problema.

Ao tratar deste tema, por mais de uma vez tive a oportunidade de citar o jornal 0 Mulato ou o Homem de Cor que publicou em 4 de novembro de 1833:

"Não sabemos o motivo porque os brancos moderados nos hão declarado guerra, há pouco lemos uma circular em que se declara que as listas dos Cidadãos Brasileiros devem conter a diferença de cor e isto entre homens livres!..."23.

Trata-se, de fato, de uma forma especifica e relativamente original de racialização das disputas em torno dos significados da cidadania na jovem monarquia brasileira. A igualdade entre os cidadãos livres, reivindicada pelas populações livres "de cor", implicava, contraditoriamente, no silenciamento sobre a própria cor, que permanecia como marca de discriminação. Uma reivindicação de silenciamento que se fazia, entretanto, de forma politizada e muitas vezes ameaçadora. Desta maneira, do ponto de vista dos interesses escravistas, a construção de qualquer justificativa racializada da permanência da instituição escravista mostrava-se simplesmente explosiva.

Este foi um limite que a virada conservadora, que se seguiu à maioridade de Pedro II, não se atreveu a ultrapassar. É dentro deste contexto que me parece deve ser interpretada a vitória camponesa na Guerra dos Marimbondos. 